\title{
CATOLICISMO Y PERONISMO. IGLESIA CATÓLICA Y ESTADO EN LA ARGENTINA, 1945-1955.
}

\author{
Susana BIANCHI \\ IEHS, UNCPBA
}

En las últimas décadas del siglo XIX, a partir del Concilio Vaticano I (1869-1870) -con la consolidación del poder papal y la resolución de enfrentar al liberalismo- y a partir de la Comuna de París -en la que se percibió una descamada «lucha de clases»- los católicos surgieron como un activo sujeto político, dispuestos a plasmar soluciones concretas en las más diversas áreas de la vida social. La Argentina no quedó al margen de este «catolicismo político» (1) que, enfrentado con las instituciones liberales, buscaba saltar el espacio creado por la secularización. Si bien al principio la movilización fue defensiva, ya en las primeras décadas del siglo XX comenzó a cobrar autonomía con el objetivo de resolver el problema de fondo: cómo transformar al catolicismo en el principio organizador del cuerpo social. A partir de allí, la cuestión de la relación entre la Iglesia y el Estado -de un Estado que además englobaba en forma creciente espacios considerados propios de la sociedad civil- se planteó como la cuestión central.

En la Argentina, durante la década de 1930 y comienzos de la 1940, la sociedad parecía haber mudado su fisonomía. En Buenos Aires, el aspecto más visible de la transformación social fue la irrupción de nuevos sectores populares, producto de las migraciones internas, percibidos como un tumor que crecía adosado a la sociedad «normalizada», la que además no tardó en verse como una sociedad fracturada' (2). Desde la perspectiva eclesiástica, el problema mayor radicaba en la clara ruptura que existía entre el catolicismo y los sectores populares: «si hay dos términos sociales opuestos, si hay dos sectores en nuestros días que se han declarado guerra implacable, son sin duda el capital y el trabajo. Ahora bien, todo el mundo sabe que el obrero ha aliado en su mente el capital con la Iglesia, de suerte que el abismo que separa el capital del trabajo es el mismo que separa a los trabajadores de la Iglesia» (3). Dentro de esta perspectiva, el ascenso del peronismo fue percibido como la posibilidad de saltar el abismo: implementar los aparatos de Estado como medio de acercamiento a diferentes sectores sociales, permitiendo de este modo establecer la hegemonía del catolicismo como principio fundante de la sociedad.

\section{«Cristianizar al peronismo».}

La posibilidad de una acercamiento entre la institución eclesiástica y los gestores del naciente peronismo se abrió a partir de dos consideraciones. En primer lugar, el peronismo era visualizado como el proyecto político del Ejército. La idea de la unidad entre la Iglesia y las fuerzas armadas tenía larga data dentro del pensamiento político católico. Comenzó a articularse a partir del 
momento en que las revoluciones de 1848 señalaron la emergencia de las «clases peligrosas»: según Donoso Cortés, contra el socialismo y el comunismo, la Iglesia y los ejércitos constituían el único sostén de la civilización contra la barbarie (4). En la Argentina, la idea de esta unidad se había consolidado en la década de 1930. Una relación más fluida entre la Iglesia y el Ejército -que comenzó a abandonar las tradiciones liberales y masónicas- pudo ser establecida a través del temor común a la amenaza de comunismo y a la progresiva identificación entre el catolicismo y la nacionalidad, abonada en la reivindicación del hispanismo.

En segundo lugar, la posibilidad de la alianza radicaba en el amplio arco de coincidencias que presentaban sus proyectos de sociedad. Tanto la doctrina social de la Iglesia como el peronismo reconocían la realidad de los conflictos sociales y proponían su superación a través de una conciliación de clases en la que el Estado jugaba un papel central: por un lado, como mediador en los conflictos, pero fundamentalmente implementando una política redistributiva que tanto el peronismo como la Iglesia definían como «justicia social». Dentro de esta perspectiva, el peronismo era considerado, además, como una eficaz barrera para el avance del comunismo.

En esta línea, en noviembre de 1945, una Pastoral Colectiva del Episcopado, recordando a los fieles la prohibición de votar a partidos políticos que sostuvieran la ley de divorcio y la separación del la Iglesia y el Estado, fue percibida sin demasiado margen de error como la condena a la Unión Democrática -a la que se presentaba como peligrosamente semejante a los Frentes Populares- y el explícito apoyo a la candidatura de Juan Domingo Perón. Este apoyo no dejó de producir fuertes reticencias dentro de las mismas filas eclesiásticas por las ambiguiedades que para muchos ofrecía la figura de Perón -muy distante del ideal del «militar católico»-como por el excesivo obrerismo de sus políticas. Sin embargo, se consideraba que los peligros podían ser alejados: sólo era necesario, como señalaba enfáticamente el presbítero Virgilio Filippo, «cristianizar al peronismo (5)».

\section{Los campos del conflicto}

Desde que Perón asumió la presidencia (4 de junio de 1943), la Iglesia católica mantuvo una fuerte presencia dentro del espacio público, mientras el gobierno hacía un gran despliegue de sus buenas relaciones con la jerarquía eclesiástica. Hubo una publicitada asistencia de Perón y de su esposa a misas de campaña y se incluyó un oficio religioso en la primera celebración del 17 de octubre; se designó a la Virgen de Luján protectora de la Policía Federal y se entronizó su imagen, después de la nacionalización, en todas las estaciones ferroviarias; se apoyó oficialmente al Primer Congreso Mariano Nacional, lo mismo que a la exposición del Museo Histórico de la Iglesia; los obispos fueron recibidos frecuentemente en el despacho presidencial; se declaró la festividad de Santa Rosa de Lima como día de Acción de Gracias; se designó a San José de Calazans como patrono de las escuelas argentinas, y la enumeración puede 
continuar. Por su parte, la Iglesia retribuía las manifestaciones de apoyo: la presencia de Santiago Luis Copello, arzobispo de Buenos Aires y cardenal primado de la República Argentina, era constante en todos los actos oficiales.

En 1946, además, el gobiemo elevó una solicitud oficial al Vaticano -la Argentina fue el único país que lo hizo-para pedir la proclamación del dogma de la asunción de la Virgen María en cuerpo y alma a los cielos. Ante esto fue muy explícita la satifacción de algunos miembros de episcopado: «Este noble gesto de nuestro gobierno interpreta y honra la tradición cristiana y mariana de nuestro pueblo y nos llena de profunda y sentida satifacción, dándonos la seguridad que será prenda de abundantes y preciadas bendiciones de la Madre de Dios para nuestra querida Patria, que tan honrosamente y como Nación se une así a los anhelos del orbe cristiano» (6). De esta manera parecía ratificarse la identidad que se establecía entre catolicismo y nacionalidad.

Sin embargo; muy pronto se advirtió que la tarea de «cristianizar al peronismo» no iba a ser sencilla. Más allá de las múltiples manifestaciones mutuas de apoyo, empezaban a esbozarse los campos del conflicto. Ya desde comienzos del gobierno de Perón, en 1946, numerosos actores de la institución eclesiástica comenzaron a observar con preocupación lo que consideraban avances del Estado sobre la sociedad civil, fundamentalmente sobre aquellas áreas que la Iglesia tenía particular interés en controlar. De allí que muy pronto comenzaran las denuncias sobre lo que se definía como «estatismo.» Uno de los intelectuales más relevantes del catolicismo argentino, monseñor Gustavo Franceschi, podía de esta manera señalar que «De acuerdo con las enseñanzas sociales católicas siempre hemos sostenido que las organizaciones del gobierno no tienen derecho a intervenir en las actividades de las instituciones privadas. Es misión del Estado ayudar pero nunca absorber completamente al sector privado (7)».

En relación a los avances del Estado sobre las «instituciones privadas», una de las primeras reacciones católicas estuvo vinculada a la sanción de la ley de Asociaciones Profesionales. Firmado por el presidente de la Junta Central de la Acción Católica, 'se elevó un petitorio a la Cámara de diputados denunciando «... esta tendencia de monopolio sindical con la concesión de toda clase de privilegios a la asociación reconocida con personeria gremial, en menoscabo de las demás asociaciones minoritarias» (8). La preocupación radicaba en 'la negativa a reconocer, según disposiciones de la ley, a aquellas organizaciones sindicales que se constituyesen en base a credos religiosos, lo que constituía el fin toda intención de crear un «sindicalismo católico».

Pero la protesta no fue demasiado insistente. La Iglesia no parecía dispuesta a presentar batalla en un campo, como el sindicalismo, en el que nunca había tenido mayores éxitos y al que ya consideraban perdido. Por otra parte, se estimaba que la «peronización» de los sindicatos era una sólida barrera ante los avances comunistas. Algunos años más tarde, el presbítero Hernán Benítez evaluaba los resultados: «En el campo del adoctrinamiento o de la formación de 
élites obreras no es menor la desproporción entre la acción del gobierno y la del catolicismo. De éste lo más representativo es la JOC [Juventud Obrera Católica], meritísima institución, por cierto, la que admiro con el fondo del alma pues realiza, a mi ver, el más inteligente apostolado de este tiempo; pero pequeña, pequeñísima frente a la explosión de universidades obreras, escuelas fábricas y unidades básicas consagradas con todos los recursos a la educación de los trabajadores. La situación de la Iglesia en lo sindical, mutual, social y en la formación de las elites, según lo dicho, parecería gravísima y lo sería si el movimiento peronista no se hubiera presentado tan cristiano... Se nos ha servido en bandeja un mundo obrero...» (9).

En síntesis, la cuestión de las organizaciones obreras no se transformó en el eje del conflicto. Incluso, todavía se esperaba la posibilidad de poder «cristianizar» a los sindicatos peronistas. Desde la perspectiva eclesiástica, los problemas mayores surgieron ante los avances del estatismo en áreas que era consideradas de su más estricta incumbencia, fundamentalmente aquellas que eran percibidas como básicas para la implementación del proyecto que buscaba colocar a la religión como el principio organizativo de la sociedad: la educación, la familia, las organizaciones femeninas y juveniles, y la asistencia social.

Dentro del campo de la educación el amplio margen otorgado a la Iglesia católica se expresó en la aprobación de la ley de enseñanza religiosa en las escuelas públicas (10). Sin embargo, la implementación de esta ley fue, desde el comienzo, objeto de múltiples conflictos de tipo juridiccional entre la Iglesia y el Estado: gobierno peronista no estaba dispuesto a dejar de controlar la designación de los funcionarios de la Dirección Nacional de Enseñanza Religiosa, ni de los profesores encargados de enseñar religión en las escuelas. De este modo, los católicos muy pronto podían denunciar que «se trata de una educación religiosa impartida por el Estado, con sus propios maestros y bajo su propia dirección» (11), donde la Iglesia tenía escasa incumbencia.

Además, pronto también los católicos advirtieron los límites que se presentaban para la enseñanza religiosa: desde la mala formación de los docentes (12) hasta el mantenimiento de lo que se consideraba una concepción «iluminista» de la enseñanza: «¿qué alcance puede tener el curso de catolicismo, si en los de cosmogonía, filosofía y literatura o historia se destruyen las concepciones del mismo?» (13). Pero los límites se percibían no sólo en las persistencias sino también en las innovaciones. La introducción de la «escuela activa» (14) la obligatoriedad de la enseñanza de la higiene, el impulso dado a la práctica de deportes (15) eran cuestiones que, desde la perspectiva eclesiástica, estaban demasiado centradas en lo corporal pudiéndose, por lo tanto, deslizárse a terrenos vedados.

De esta manera, los católicos podían denunciar: «La Religión no es para nosotros una asignatura más, sino que es una enseñanza que debiendo servir de base a la vida misma y a todas las actuaciones del hombre debe reflejarse en el resto de la enseñanza y la educación [...] Esto supone evidentemente no sólo 
agregar la Religión a las asignaturas de las Escuela sino también que estas mismas asignaturas se enseñen siempre iluminadas e informadas por la doctrina y el espíritu de aquélla» (16). Sin embargo, quedaba muy claro que el gobierno peronista no estaba totalmente dispuesto a que la educación fuera totalmente «iluminada» por el catolicismo.

En efecto, desde la perspectiva eclesiástica, el principal límite a la enseñanza religiosa podía encontrarse en el mismo carácter que paulatinamente asumió la política educativa: los avances de la creciente «peronización» de la enseñanza, que se buscó impulsar, sobre todo, en el ámbito de las escuelas primarias. Los textos escolares pusieron su acento en dos cuestiones: en primer lugar, la comparación entre el peronismo y el mismo Perón con distintos episodios y personajes de la historia nacional; en segundo lugar, la glorificación de las obras del peronismo en el poder, con énfasis tanto en la obra de Perón como la de Eva Perón (17). Un anticipatorio y buen ejemplo se podía encontrar ya en 1947, en un texto que tenía como objetivo explicar el Plan Quinquenal a los niños:

«Así como tu sueñas en las glorias pasadas de la Patria, así también otros niños, en los siglos venideros, soñarán con la gloria del presente y envidiarán tu suerte.

«Porque tu estas viviendo en los años del gobierno del GENERAL PERON, que es

como Belgrano, un patriota cristiano; como San Martín, un libertador preclaro;

como Rivadavia, un genial propulsor del progreso;

como Sarmiento, un apóstol de la cultura;

Pero hay algo en lo que no tiene antecesor.

«Es, como nadie, el DEFENSOR de los trabajadores y el PALADIN DE

LA JUSTICIA SOCIAL

«Abre tus ojos, niño, para ver la gloria presente de tu Patria hermosa» (18).

Dentro de esta línea fueron los principios del peronismo, centrados en la exaltación a sus líderes, y no los de la religión -que quedó reducida a unas pocas horas semanales de las llamadas clases «especiales» (19)- lo que constituyeron la base de las políticas educativas de «la nueva Argentina».

La preocupación de la Iglesia se manifestó también en aquellos avances del «estatismo» en areas privadas, consideradas de su exclusiva incumbencia. $Y$ en este aspecto, el tema de la familia ocupó un lugar central (20). El peronismo compartía con el catolicismo una misma concepción de la familia. Según Raúl Mendé, en la Convención de 1949 -que además incorporó los «Derechos de la Familia» a la Constitución Nacional-, «la naturaleza ha fijado imperiosamente los puestos dentro de la institución familiar, asignando al padre la autoridad y la providencia, a la madre el amor y la ternura y a los hijos la obediencia y el 
respeto, en una armonía... Este ordenamiento es ordenamiento natural. Este ordenamiento es ordenamiento cristiano. Este ordenamiento es el ordenamiento tradicional argentino» (21). Pero estos acuerdos en cuanto a las conceptualizaciones no impidieron los conflictos.

El núcleo familiar se constituyó en el eje articulador de numerosas políticas redistributivas del peronismo: desde salario familiar hasta planes de vivienda. Además, en un país con baja densidad demográfica, el peronismo impulsó una decidida política natalista: protección a la natalidad, asistencia pre y post natal al niño y a la madre, severa represión del aborto y de los métodos anticonceptivos, regulación de la actividad extradoméstica de las mujeres. En sí mismas, estas políticas reforzaban una concepción de la vida familiar afín al catolicismo. Sin embargo, provocaron la desconfianza eclesiástica en la medida en que se adviertía una excesiva ingerencia del estado en un área considerada de dominio exclusivo de la Iglesia.

De esta manera, los católicos no dudaban en denunciar: «Existe otra concepción [sobre la familia] no menos aberrante [...]: la concepción estatal, en virtud de la cual lejos de despreciar a la familia, el Estado asume un papel protector y aparentemente robustecedor de aquella. Aparentemente, hemos dicho, porque como muy bien lo hace notar el Arzobispo, 'Observaréis lo artero del raciocinio: se mencionan constantemente el hogar, el salario familiar, las tareas domésticas, el derecho de la madre, sobre todo, la natalidad. Fácil sería dejarse engañar por esta apariencia. Mas de hecho lo que se persigue es una negación de la familia, bajo la fachada de semejante propaganda, cuya aparición súbita e insistencia reiterada no habrá dejado de sorprendernos' [...] Corolario de ella es 'una familia sin padre ya que el esposo ha sido sustituido por el Estado'. Hay también la concepción utilitarista en virtud de la cual, tenida en cuenta la necesidad de acrecentar el número de ciudadanos, se realiza una amplia prédica en favor del aumento de la natalidad, pero quitando paulatinamente, el niño a la madre, de suerte que so pretexto de 'descargar a la madre' de sus pesadas tareas, el Estado poco a poco se sustituye a ella» (22).

En esta línea, el tema de la familia se constituyó desde muy temprano y en forma casi permanente en un tema de conflicto, que tuvo sus puntos más críticos en el proyecto gubernamental de conceder a la concubina los derechos de previsión social al fallecimiento del titular (1946); en la reforma del Código Civil que reemplaza la denominación «hijos adulterinos e incestuosos» por «hijos naturales» (1946), en la reforma del artículo 7 de la ley de matrimonio civil (1947) y en la ley de equiparación de los hijos legítimos e ilegítimos (1952). Eran medidas que, en un país sin ley de divorcio, con numerosas uniones de hecho, intentaban adaptar a legislación a la realidad que la sociedad ofrecía.

Es cierto que las presiones eclesiásticas muchas veces frenaron el tratamiento de estos proyectos. Sin embargo, desde la perspectiva católica resultaban evidentes, desde muy temprano, las dificultades para instrumentar los aparatos del Estado con el objetivo de transformar a la religión en el principio 
organizador de la sociedad. A comienzos de 1948, se publicaba un documento al que se tituló precisamente «Todo lo que el Estado debe asegurar a la Iglesia,» donde se explicitaban los reclamos al mismo tiempo que las diferencias. Entre las condiciones necesarias que se exigían -en cuya base se colocaban la «libertad» y «posibilidad de acción» de la Iglesia, que debían ser garantizadas por el Estado- figuraban precisamente «aquellas condiciones materiales y espirituales que favorecen la tutela de la familia cristiana» (23).

Los avances del Estado fueron denunciados también en otras cuestiones, como la referida al papel que las mujeres debían jugar dentro de la sociedad tema que tanto para la Iglesia como para el peronismo está indisolublemente ligado al de la familia. La maternidad que el Estado procuraba alentar fue considerada incompatible con la incorporación de las mujeres al mercado de trabajo. De este modo, el peronismo procuró desalentar todo aquello que alejara a las mujeres de «su destino y de su misión». En La Razón de mi vida, un capítulo -llamado precisamente «El hogar o la fábrica»- es particularmente explícito acerca de cuál debía ser la opción: «Todos los días millares de mujeres abandonan el campo femenino y empiezan a vivir como hombres. Trabajan casi como ellos. Prefieren, como ellos, la calle a la casa. No se resignan a ser madres ni esposas. (...) Sentimos que la solución es independizarnos y trabajamos en cualquier parte, pero ese trabajo nos iguala a los hombres y ¡no! no somos como ellos (...) Por eso el primer objetivo de un movimiento femenino que quiera hacer bien a la mujer, que no aspire a cambiarlas en hombres, debe ser el hogar» (24).

En síntesis, el peronismo reforzó las ideas dominantes acerca de la posición de las mujeres dentro del núcleo familiar con fuertes puntos de contacto con las ideas de la Iglesia católica. Sin embargo, cuestiones como el sufragio femenino -a pesar de que la Iglesia católica afirmaba este derecho al considerarlo, como el peronismo, un factor moralizante para la sociedad- y fundamentalmente la aparición de organizaciones de mujeres con claro signo partidario como el Partido Peronista Femenino (25), fueron observadas con creciente desconfianza. Se temía que la politización femenina privara a la Iglesia católica de su influencia sobre la tradicional piedad de las mujeres. De este modo, no tardaron en aparecer las advertencias: «el acto de votar no significará tomar parte activa en la lucha política, ni acudir al comité, ni a la plaza, ni decir discursos ni abandonar el hogar para dedicarse a la vida partidaria. Este acto tan breve de depositar una lista en una urna cada tanto tiempo no causará el menor trastorno en la vida de una mujer» (26).

La Iglesia además podía contabilizar, dentro de sus espacios perdidos, el de la asistencia social. La Sociedad de Beneficencia de Buenos Aires había sido intervenida, al Patronato de la Infancia se le habían retirado los subsidios y las instituciones caritativas vinculadas a la Iglesia no podían competir frente la poderosa y eficaz Fundación Eva Perón que invadió el campo asistencial otorgándole un vigoroso signo político. Además la Fundación era indisociable de la persona de Eva Perón, que constituía una de las figuras del peronismo más irritativas para amplios sectores eclesiásticos. 


\section{El conflicto en el campo de la religión}

Los conflictos tendieron a generalizarse a partir de 1950, cuando también comenzaron a reducirse las manifestaciones mutuas de apoyo entre el Estado y la Iglesia. Si bien las relaciones entre ambas cúpulas mantuvieron su formalidad, esto no lograba ocultar el conflicto de fondo. De esta manera, comentando una Pastoral colectiva de la Iglesia de Bolivia, la Iglesia podía señalar: «Los males descriptos por la jerarquía boliviana pueden aplicarse provechosamente a otros países latinoamericanos que detrás de una aparente armonía entre el gobierno y la religión, presentan un clima de mutuo descontento que es potencialmente explosivo. Sin embargo, por lo general se lo tolera y se lo pasa por alto en las relaciones oficiales entre los dos poderes» (27).

Si algunos sectores eclesiásticos habían esperado una mayor apertura de sus espacios con la reforma constitucional de 1949, estas expectativas se habían visto frustradas. En rigor la reforma se limitó a incorporar al texto constitucional, un artículo que permitía la reelección presidencial y las declaraciones de derechos sociales. Si bien mantuvo la posición privilegiada del catolicismo religión que debe sostener el Estado y a la que debe pertenecer el Jefe de Estadomantuvo los principios que desde la perspectiva eclesiástica eran contradictorios con dicha posición: la libertad de cultos, el derecho de patronato y principios iluministas y liberales, como el de la soberanía popular. Indudablemente, el gobierno peronista no estaba dispuesto a que el catolicismo se transformara en «el contenido ético del Estado».

Pero el conflicto fundamentalmente se agravó a partir del momento en que la Iglesia comenzó a considerar que, a pesar del estatuto privilegiado que el catolicismo debía gozar en el país, el gobierno peronista había comenzado a otorgar demasido espacio a otros credos religiosos. Según la Iglesia, «Si hay una verdad cierta e indiscutible entre los principios generales del derecho público eclesiástico es la del deber de los gobernantes, en un Estado compuesto en su casi totalidad por católicos y consiguientemente, gobernado por católicos, de informar la legislación en sentido católico. Lo que implica tres inmediatas consecuencias: 1) La profesión social y no solamente privada de la religión del pueblo; 2) La inspiración cristiana de la legislación; 3) La defensa del patrimonio religioso del pueblo contra cualquier asalto de quien quisiera robarle el tesoro de su fe y de la paz religiosa» (28). En síntesis, se consideraba que el gobierno no cumplía con su deber de defender el «patrimonio religioso».

El antisemitismo católico se había mantenido incólume dentro de las filas del peronismo. Tanto el presbítero Virgilio Filippo -designado Adjunto Eclesiástico de la Casa de Gobierno y, desde 1948, diputado nacional- como el jesuita Hernán Benítez -representante de Perón ante el Vaticano en 1947, asesor de la Fundación Eva Perón y director de la revista de la Universidad de Buenos Aires- insistían, en frecuentes ocasiones, en aplicar los adjetivos «judío» y «sinagogal» como calificativos denigrantes (29). Joaquín Díaz de Vivar, 
diputado peronista, defensor de la ley de enseñanza religiosa en la Cámara de Diputados también insistía, aún en 1947, en considerar al nazismo como opción frente al peligro del comunismo (30).

Estas actitudes no fueron obstáculo para que, desde 1946, Perón fuera el primer presidente en saludar a la comunidad judía con motivo de la celebración de Año Nuevo, ni para que se les haya otorgado asueto a los soldados judíos en sus fechas religiosas, ni para las fuertes condenas a los atentados racistas. Además, la Constitución del 49 incluyó un artículo de clara condena a la discriminación racial y religiosa y en 1950, el gobierno argentino ratificó la Convención sobre genocidio, aprobada por la ONU (31) También las relaciones con el Estado de Israel se manifiestaron fluídas. No se tardaron en entablar relaciones diplomáticas y, en 1954, Ariel León Kuvoby, ministro plenipotenciario agradecía al gobierno «el apoyo expresado en embarques que se realizaron por voluntad de Eva Perón» (32).

Si bien estas relaciones no dejaron de perturbar a aquellos sectores católicos que desde comienzos de siglo denunciaban a la inmigración judía como un atentado en contra de la nacionalidad, el conflicto en el campo de la religión surgió no por estas cuestiones, sino por el avance de ciertas formas religiosas que competían eficazmente con el catolicismo dentro de los sectores populares. Y el conflicto se entabló en la medida en que el gobierno no sólo no cumplía con su deber de defensa del «patrimonio religioso», sino que favorecía el desarrollo de las religiones disidentes (33).

Entre las formas de religiosidad que se desarrollaron en este período se encontraba el espiritismo, en una versión local comocida como la Escuela Científica Basilio, a la que el gobierno otorgó personería jurídica y por la que el general Perón sentía una inocultable simpatía. Además, muchos católicos no dudaban de que el incremento de las prácticas espiritistas estaban estrechamente vinculadas al apoyo les otorgaba desde el Estado:

«los componentes de la nombrada secta espiritista, a todas luces de dudosa solvencia, aparecen sin embargo, financiando una propaganda tan profusa como costosa: distribución de plaquetas de aluminio (metal cuya tenencia y empleo, según común opinión, debe ser autorizada por resorte estatal) como distintivos espiritistas, en subterráneos y demás lugares de gran afluencia de público; gigantescos letreros iluminados con la leyenda 'Jesús no es Dios' colocados en sitios estratégicos de la ciudad; material empapelamiento de muros con affiches, preferentemente en torno a determinados templos católicos; reparto de folletos descristianizantes a la salida de escuelas del Estado donde por ley se imparte enseñanza religiosa... Todo esto constituye un extraño y alarmante conjunto que obliga a una detenida puntualización de los hechos» (34).

De esta manera, el primer conflicto abierto entre la Iglesia y el gobierno peronista estalló a raíz de un multitudinario acto que Escuela Científica Basilio organizó en un estadio deportivo, en octubre de 1950. El acto, que había sido convocado bajo la consigna «Jesús no es Dios», considerada blasfema por los 
católicos, fue inaugurado con la lectura de un telegrama mediante el cual Perón y su esposa adherían a la celebración. Pero el desarrollo del acto se vió imprevistamente alterado: jóvenes de la Acción Católica ubicados estratégicamente en las tribunas y en las inmediaciones del estadio provocaron un considerable tumulto. Como consecuencia, la policía detuvo, por alterar el orden público, a trecientos jóvenes miembros de la Acción Católica.

Ante el explícito apoyo de Perón a un acto considerado blasfemo por los católicos, por presión de los dirigentes de la Acción Católica, el Episcopado debió pronunciarse a favor de los jóvenes que parecían haber actuado con una considerable cuota de autonomía. Además, mediante un autocardenalicio, el Arzobispo de Buenos Aires dispuso que en todas las Iglesias se debían efectuarse actos de desagravio «por la horrenda blasfemia que ha sido divulgada con profusión extraordinaria por nuestra ciudad» (35).

Poco días más tarde, llegaba al país el cardenal Ruffini, como legado papal ante el Congreso Eucarístico Nacional. Una multitud aguardó el paso de Ruffini por las calles de Buenos Aires, que lo aclamó al grito de «¡Jesús es Dios!», lema antiespiritista que deslizó su sentido al de consigna antiperonista. Para muchos quedaba claro que las manifestaciones religiosas podían tomar un sospechoso cariz antigubernamental. Una vez clausurado el Congreso Eucarístico, Perón mantuvo con el cardenal Ruffini una larga entrevista, sobre la que nada trascendió. Sin embargo, las elogiosas declaraciones de Ruffini, al partir para Europa, respecto al gobierno de Perón y al sentido cristiano en que se encaminaba la Argentina permiten suponer que también la Iglesia procuró no profundizar las divergencias. Sin embargo, el conflicto, al ubicarse en el campo de la religión, había alcanzado un punto de difícil retorno.

Al conflicto por la difusión del espiritismo, que se prolongó hasta 1955, pronto se confundió con la alarma eclesiástica por los avances del protestantismo, a través de las campañas pentecostalistas. Estas campañas se iniciaron en la Argentina en 1952, para alcanzar un un éxito masivo en 1954. La Iglesia católica había tolerado a las iglesias protestantes de origen inmigratorio en la medida en que éstas se limitasen a sus comunidades nacionales, pero no admitían ningún movimiento expansivo fuera de esos ámbitos cerrados. A partir de la fuerte identificación entre catolicismo y nacionalidad, cualquier intento por parte de estos cultos de trascender al ámbito público era automáticamente calificado como una invasión «foránea».

Pero el problema que presentaba el pentecostalismo era no sólo que no estaba vinculado a ningún grupo nacional de origen inmigratorio, sino que encontraba sus bases de reclutamiento -como el espiritismo y el peronismo- en las clases populares urbanas, a las que precisamente se buscaba «catolizar». El conflicto alcanzó su punto más alto a mediados de 1954 cuando el predicador norteamericano Theodore Hicks, que practicaba el «don de la sanidad», reunía muchedumbres en estadios deportivos de Buenos Aires. La causa de este éxito, según la perspectiva eclesiástica, radicaba en el apoyo que el gobierno había 
otorgado a la misión pentecostal, percibido en la autorización policial para la realización de las Asambleas, en el traslado de los enfermos a dichas Asambleas en las ambulancias de la Fundación Eva Perón y en la recepción que Perón hizo a Hicks en la Casa de Gobierno.

Si bien el conflicto en el campo religioso, se expresó abiertamente a través de la difusión del espiritismo, primero y del pentecostalismo después, en el mismo campo puede ubicarse el conflicto central: la intencionalidad del peronismo de presentarse como un valor moral que asumía la forma de una peculiar religiosidad. A partir de 1951, comenzó a publicarse Mundo Peronista, revista que perseguía objetivos de consolidación ideológica, en el momento en que el gobierno peronista empezaba a enfrentarse con una serie de dificultades. Desde la revista, la identificación con el peronismo no fue presentada como la adhesión a una abstracta causa política, sino como una adhesión incondicional a las figuras de sus líderes que fueron revestidos con rasgos de sacralidad.

La enfermedad y la muerte de Eva Perón, en 1952, acentuó la incorporación de tọda una símbología religiosa: rezar por Eva Perón, hacer peregrinaciones por su salud, escribirle oraciones, eran conductas altamente valoradas. Sin embargo, estas actitudes no se redujeron a la figura de Eva Perón, ni tuvieron origen en su temprana muerte, revestida además de rasgos de martirologio. Desde la revista, se impulsaba la construcción de altares durante su vida, que debían incluir, en primer lugar, la figura de Perón.

La sacralización de las figuras políticas más significativas permitió que la adhesión al peronismo fuese descripta en términos de «devoción», «fervor», "veneración», $y$ "fe». $\mathrm{Y}$ el mismo peronismo podía ser explícitamente presentado como una forma de revelación o conversión religiosa. De esta manera un adherente al peronismo era descripto como «un hombre que es todo un ejemplo de devoción por el Líder... Su profesión: obrero y predicador de la Doctrina Peronista [que trata] como su más humilde discípulo, de llevar la luz a los que todavía no han llegado a ver la verdad...» (36). Ser peronista significaba, por lo tanto, asumir el peronismo como una nueva forma de religiosidad, que incluso podía desplazar las formas de la religión institucional. Mundo Peronista podía incluso invitar a sus lectores a un momento de «meditación», a partir de textos como el siguiente:

«iSeñor! Se dice que sois Dios porque diste la vista a los ciegos. [...]

«Se dice que sois Dios porque limpiáis al leproso. [...]

«¿No hacen, Señor Jesucristo, otra cosa tus bondades? ¿Haces que se crea como Evangelio la verdad en el haraposo, que al pobre se le escuche, que el jorobado haga figura, que al astra se le atienda, y que de la boca del pobre salga también la razón y la verdad? [...]

«MARAVILLA PERONISTA que Perón ha realizado en la Argentina, poniendo en práctica la ley de amor, dada, como dice el apostol a los hijos de Dios sobre las tablas de su corazón» (37). 
En síntesis, si el peronismo había comenzado presentándose a sí mismo inspirado en el cristianismo, ya a comienzos de la década de 1950 podía presentarse como equivalente o en pie de igualdad con el cristianismo, frente a la irritación eclesiástica.

\section{La crisis}

Los conflictos con el gobierno peronista no dejaron de repercutir dentro de la institución eclesiástica. Frente a una jerarquía eclesiástica cada vez más fracturada entre los que claramente se definían como antiperonistas y los que buscaban no profundizar los conflictos para no perder lo que se consideraba posiciones ganadas, sectores del clero y de laicos -en particular, la Acción Católica Argentina- presionaban a los obispos para que se definiera explícitamente frente lo que se consideraban ataques a la religión. Incluso, algunos grupos de laicos comenzaron ya desde comienzos de la década de 1950 las gestiones necesarias para agruparse como fuerza política alternativa, constituyendo el Partido Demócrata Cristiano (1954). De esta manera, si los adversarios del peronismo veían cada vez más reducirse sus medios de acción en un régimen que acentuaba sus rasgos totalitarios, la Iglesia católica se presentaba como un posible espacio de oposición.

Dentro de ese clima, en noviembre de 1954, Perón convocó a una reunión a funcionarios del gobierno, legisladores y representantes del Partido Peronista, con el objetivo de informarles sobre el estado de la «oposición». Pero a las consabidas referencia a los adversarios políticos y a los estudiantes universitarios agregó nuevos elementos: la Acción Católica Argentina y varios miembros del clero. Entre los nombres de los sacerdotes considerados opositores figuraban dos miembros del episcopado: Fermín Lafitte, arzobispo de Córdoba, y Froilán Ferreyra Reinafé, obispo de La Rioja. Indudablemente la denuncia implicaba un tono amenazante: "Aquí hay como diez y seis mil integrantes del clero. Cómo vamos a hacer una cuestión porque haya 20 o 30 que sean opositores? Es lógico que entre tantos haya algunos. Qué es lo que tenemos que hacer? Hay que tomar medidas contra esa gente. Tiene razón la jerarquía eclesiástica cuando me dice que no es la Iglesia sino que son algunos curas descarriados de la Iglesia. Nosotros vamos a ayudarlos para que los pongan en su lugar...» (38).

Pocos días más tarde, la Confederación General del Trabajo organizó un masivo acto para reiterar la adhesión a Perón frente a los «ataques católicos». Las pancartas con leyendas como «Perón sí, curas no», «Cuervos a la Iglesia» eran expresivas del fuerte carácter anticlerical que se le imprimió al acto (39). Por su parte, el Episcopado había dado a conocer una Carta Pastoral en la que, en primer lugar, señalaba que «ningún sacerdote puede ni debe tomar parte en las luchas de partidos políticos sin comprometer su investidura y a la misma Iglesia», mientras recordaba que la Acción Católica debía mantenterse «siempre 
fuera y por encima de los partidos políticos». Pero también se agregaba que «frente al comunismo ateo y materialista, frente al divorcio absoluto, frente ala escuela laica y obligatoria, como a otras cuestiones esenciales de la doctrina, ningún sacerdote podría permanecer indiferente sino que debería asumir la defensa serena y firme de los valores eternos». Diferenciaba de este modo, «la política» de la «defensa obligada del Altar» (40). De esta manera, tras fracasar las gestiones realizadas por el Nuncio Apostólico frente al Ministerio del Interior, la guerra había quedado declarada, mientras la Iglesia alentaba a los católicos recordando que «Cristo resucita al tercer día, pero sus enemigos mueren definitivamente» (41).

La ofensiva peronista se trasladó entonces al Congreso donde muy pronto se aprobaron una seriẹ de leyes que afectaban los intereses más caros de la Iglesia, como la supresión de la enseñanza religiosa y la implantación del divorcio, al mismo tiempo que se presentaba un proyecto de ley que proponía modificar la Constitución para establecer el principio de separación entre la Iglesia y el Estado. Un decreto además establecía que los actos religiosos serían permitidos únicamente en lugares cerrados. Además, el Poder Ejecutivo podía impedir la celebración de cualquier acto cuando «mediare peligro inminente de alteración del orden o de la tranquilidad pública, o cuando la celebración fuese contraria a los intereses del pueblo» (42). Indudablemente la Iglesia quedaba fuera del espacio público y las protestas eclesiásticas ya no tenían cabida dentro del gobierno.

Mintras las denuncias se sucedían y el conflicto se profundizaba, en junio de 1955, debía celebrarse la festividad de Corpus Christi. Pero el gobierno prohibió que se realizara la procesión pública: los actos debían efectuarse dentro del recinto de la Catedral de Buenos Aires (43). A pesar de esto la celebración convocó a una verdadera multitud que, aclamando a «Cristo Rey», desbordó ampliamente la capacidad de la Catedral. Muy pronto los acontecimientos se volvieron ingobernables, incluso para las autoridades eclesiásticas (44). Los congregados se lanzaron por las calles de Buenos Aires: apedrearon sedes de diarios oficialistas, destrozaron vidrios de edificios públicos, con pinturas de alquitrán consignaron «Muera Perón» y «Viva Cristo Rey» y al llegar frente al Congreso, arrancaron una placa de homenaje a Eva Perón y arriaron la bandera nacional para enarbolar la bandera papal (45).

La Iglesia católica ya era explícitamente el espacio de oposición. Cuando el 16 de junio de 1955, el ejercitó intentó un frustrado golpe con el objetivo de derrocar a Perón pocos dudaron de la complicidad católica. La reacción peronista no ese hizo esperar y esa misma noche fueron asaltados e incendiados la Curia Metropolitana y varios templos del centro de Buenos Aires. Al día siguiente, la Secretaría de Estado del Vaticano daba a conocer el decreto de excomunión de Perón. Según recordaba un calificado testigo católico, «hasta los más escépticos comprendieron que sólo quedaba abierto el camino a la revolución» (46). 
De esta manera, la Iglesia católica estuvo nuevamente junto a las Fuerzas Armadas, el 16 de septiembre de 1955, en la «Revolución Libertadora», levantamiento militar que derrocó al gobierno peronista. Un dato particularmente notable es la adopción de una explícita simbología religiosa adoptada por los militares sublevados -los aviones desde Córdoba llegaban a Buenos Aires bajo la consigna «Cristo Vence»- y la premura en otorgar, pese al apoyo dado a la revolución por laicistas, como radicales, socialistas y demoprogresistas, las principales reivindicaciones eclesiásticas como la suspensión de la ley de divorcio. Indudablemente la Iglesia católica había consolidado su posición como actor político en la sociedad argentina.

\section{NOTAS.}

(1) Para la definición del catolicismo político, Javier TUSELL: Franco y los católicos, Madrid, Alianza, 1984, p. 14.

(2) José Luis ROMERO, Latinoamérica, las ciudades y las ideas, Buenos Aires, Siglo XXI, 1976, p. 331.

(3) Conferencia de Monseñor Emilio di Pasquo en las Jornadas de Vocaciones Sacerdotales (1945), Revista Eclesiástica del Arzobispado de Buenos Aires, abril de 1946, p. 307.

(4) Friederich HERR, «Problemas del catolicismo», en Europa, madre de revoluciones, Madrid, Alianza, 1980, p. 653.

(5) Citado por Hugo Gambini, El peronismo y la Iglesia, Buenos Aires, Centro Editor de América Latina, 1971, p. 17.

(6) «Carta Pastoral de S.E. Cardenal Caggiano, obispo de Rosario», en Orden cristiano, 120, octubre de 1946, $2^{\circ}$ quincena, p. 1237.

(7) Criterio, 959, $1^{\circ}$ de agosto de 1946, p. 112.

(8) «La Acción Católica Argentina formula reparos al decreto sobre organización y funcionamiento de las asociaciones profesionales obreras», en Orden Cristiano, 121, noviembre de 1946, $1^{\circ}$ quincena, p. 23.

(9) Hernán BENITEZ, La aristocracia frente a la revolución, Buenos Aires, s/ e, 1953 , p. $366-367$.

(10) Susana BIANCHI, «Iglesia Católica y Estado durante los gobiernos peronistas: la cuestión de la enseñanza religiosa», E.I.L.A., Universidad de Tel Aviv, 1991.

(11) «Reglamentación de la enseñanza religiosa» en Orden Cristiano, 141, septiembre de $1947,1^{\circ}$ quincena, pp. 67-68. 
(12) Gustavo J. FRANCESCHI, «Después de la sanción»..., Criterio, 992, 27 de marzo de 1947, p. 274.

(13) Horacio MARCO, «Posición católica ante la ley de enseñanza religiosa» en Orden Cristiano, mayo de $1947,1^{\circ}$ quincena, p. 583.

(14) Rómulo AMADEO, «La escuela activa», Criterio, 982, 9 de enero de 1947, pp. 36-37.

(15) Revista Eclesiástica del Arzobispado de Buenos Aires, 1950, p. 199.

(16) «La Iglesia quiere libertad íntegra y total de enseñanza», en Orden Cristiano, 142, septiembre de 1947, $2^{\circ}$ quincena, p. 1057.

(17) Alberto CIRIA, Política y cultura popular: la Argentina peronista (19461955), Buenos Aires, Eidiciones de la Flor, 1983, p. 219.

(18) Domingo LANANTUONI, El Plan Quincenal explicado a los niños. Buenos Aires, Edición del Autor, 1947, p. 13.

(19) Las clases «especiales»-como trabajos manuales o gimnasia- eran aquellas que por requerir una menor concentración mental figuraban en los últimos tramos del horario escolar.

(20) Susana BIANCHI, «Catolicismo y peronismo: la vida familiar como campo de conflicto", Coloquio Internacional Juan Domingo Perón, Facultad de Ciencias Sociales, Universidad de Buenos Aires, 16-18 de octubre de 1996.

(21) Convención nacional Constituyente, Diario de Sesiones, Buenos Aires, Imprenta Oficial, 1949, p. 394.

(22) Juan Francisco VIDAL, «Una pastoral en defensa de la familia» en Criterio, 987,13 de febrero de 1947 , p. 160.

(23) Revista Eclesiástica del Arzobispado de Buenos Aires, marzo de 1948, p. 138.

(24) Eva Perón, La Razón de mi vida, Buenos Aires, Peuser, 1952, p. 15. Este libro se proyectó, una vez conocido el carácter terminal de la enfermedad de Eva Perón. Estructurado como una autobiografía, el texto -que desde 1952 fue de lectura obligatoria en los establecimientos escolares primarios y secundariosestructuraba una serie de principios definidos y definitivos que permitieran suplir el discurso de Eva perón después de su muerte.

(25) Susana BIANCHI y Norma SANCHIS, El partido Peronista Femenino, Buenos Aires, Centro Editor de América Latina, 1987. 
(26) Mila FORN DE OTEIZA, «La mujer y la vida política» en Criterio, 16 de octubre de 1947.

(27) «Carta pastoral Colectiva del Episcopado de Bolivia» en Criterio, 1147, 27 de septiembre de 1951, p. 753.

(28) Revista Eclesiástica del Arzobispado de Buenos Aires, 1952, p. 349.

(29) Ver Hernán BENITEZ, «La Iglesia y el justicialismo» en La aristocracia frente a la revolución, Buenos Aires, s/e, 1953, p. 339.

(30) La Enseñanza Religiosa, Discursos pronunciados en la Honorable Cámara de Diputados de la Nación en las sesiones del 6, 7, 12 y 13-14 de marzo de 1947, Buenos Aires, 1947, p. 67.

(31) DAIA, «Medio siglo de lucha por una Argentina sin discriminaciones», suplemento de Todo es Historia, octubre de 1985, p. 10.

(32) La Prensa, 10 de mayo de 1954.

(33) Susana BIANCHI, «Catolicismo y peronismo: la religión como campo de conflicto», Boletín Americanista, 44, Universitat de Barcelona, 1994.

(34) Gustavo FRANCESCHI, «Comentarios. A quien me confesare ante los hombres", Criterio, octubre de 1950, p. 871.

(35) La Nación, 18 de octubre de 1950.

(36) Mundo Peronista, 44, junio 15 de 1953, p. 31.

(37) Ibidem, p. 44. Ver también «De corazón a corazón» en Mundo Peronista, 16 , marzo $1^{\circ}$ de 1952 , p. 32.

(38) La Nación, 11 de noviembre de 1954.

(39) La Nación, 26 de noviembre de 1954.

(40) «Carta pastoral a los Cabildos eclesiásticos, al clero diocesano y regular y a todos los fieles (23 de noviembre de 1954)», Criterio, 1224, 25 de noviembre de 1954, pp. 844-845.

(41) Gustavo FRANCESCHI, «El octavo día», Criterio, 1224, 12 de noviembre de 1954, pp. 846-848.

(42) La Nación, 22 de diciembre de 1954. 
(43) La Nación, 10 y 11 de junio de 1955.

(44) Un editorial de La Nación planteaba el problema bajo la pregunta: « ¿De quién y de dónde partió la consigna de alejarse del lugar en columna?», $L a$ Nación, 13 de junio de 1955.

(45) La Nación, 12 de junio de 1955.

(46) Mario AMADEO, Ayer, hoy, mañana, Buenos Aires, Gure, 1956, p. 35. 